\title{
Modeling Dietary Diversity Practice and Related Factors of Women Reproductive Age at Asaita Woredas, Ethiopia: Community Based Cross- Sectional Study
}

Alebachew Abebe ( $\nabla$ aleb.abebe19@gmail.com )

Haramaya University

Alebachew Abebe

Haramaya University

Research article

Keywords: Reproductive age, Dietary diversity score, Chi-square test, Odds ratio

Posted Date: November 15th, 2021

DOI: https://doi.org/10.21203/rs.3.rs-1038264/v1

License: (c) (1) This work is licensed under a Creative Commons Attribution 4.0 International License. Read Full License 


\title{
Modeling Dietary Diversity Practice and Related Factors of Women Reproductive Age at Asaita Woredas, Ethiopia: Community Based Cross-sectional Study
}

\author{
Alebachew Abebe $^{1^{*}}$ Million Wesenu ${ }^{1}$ \\ ${ }^{1}$ Department of Statistics, College of Computing and Informatics, Haramaya University, \\ P.O.Box: 138, Dire Dawa, Ethiopia. \\ "Corresponding author: Alebachew Abebe
}

\begin{abstract}
Background: Competent and health diet throughout women reproductive age is crucial for the health of both mother and new born. Dietary diversity is a procurator indicator of women reproductive age nutrient sufficiency.

Objectives: This study was planned to evaluate the dietary diversity exercise and associated factors among women reproductive age at Asaita districts, Afar region, Ethiopia.

Methods: Community based cross-sectional study was done on randomly chosen 422 women under reproductive age at Asaita woredas from February to March, 2020. Data was gathered by using interviewer and 24 hours dietary call up methods. Data entered and analyzed using SPSS version-25. Ordinary logistic regression model was employed to assess factors associated with dietary diversity and potential factors were screened at P-value less than $5 \%$.

Results: The average dietary diversity score was $4.17 \pm 1.112$ SD. Approximately 13.0\%, 78.5\% and $8.5 \%$ of women reproductive age had low, medium and high dietary diversity practice respectively. Family size of male, family size of female, marital status, education level, house with window, having cell phone, bank, refrigerator, television and cart were significant factors associated with women dietary diversity practice at $5 \%$ level of significance. The odds of being "low dietary" instead of "high dietary" multiplies by $\mathrm{OR}=0.665$ for each 1 -unit increase in family size of female household. Odds of house with window is in low dietary rather than high dietary scores are $\mathrm{OR}=2.793$ times estimated odds for house with no window's.

Conclusion: Marital status, house with window, having cell phone, owner of bank account and refrigerator had a positive association with dietary diversity whereas family size, education level, having television and cart had a negative relation with women under reproductive age of dietary diversity.
\end{abstract}

Keywords: Reproductive age; Dietary diversity score; Chi-square test; Odds ratio. 


\section{Background}

A food groups or number of individual food items that consumed over a given period of time and an essential element of diet quality is dietary diversity which reflects overwhelming a diversity of foods within and across food groups that connected with competent ingestion of necessary nutrients and upgrades good health [1-3]. In addition, ability of ensuring enough intake of vital nutrients which can encourage good health, mental development and physical through accelerating the diversity of food across and within food groups[4].

According to study done in Ethiopia[5] children and women under reproductive age are most vulnerable to malnutrition because of low dietary intakes, improper food storage and preparation, dietary taboos, inequitable distribution of food within the household, infectious diseases and care as a more specifically reason out. Dietary diversity can be ensured the improvement for the caliber of additive food that has been adverted as one of the cost effective strategies for improving health, reducing morbidity and mortality of young children as reported by world health organization[6]. One of the major public health problems in the low income and middle income countries was multiple micronutrient deficiencies, particularly for reproductive women. An increment in dietary diversity is associated with socio-economic status and household food security and a procurator blinker of maternal nutrient sufficiency and mends health outcomes for both mothers and babies is maternal dietary diversity $[7,8]$.

Source of dietary was different across the world due to accessibility of agricultural outcome, socioeconomic status and cultural practice of the community. In 2010 Food and Agricultural Organization (FAO) reported that approximately three-quarters of variety found in agricultural crops have been gone over the last century, and this erosion continues. About $90 \%$ of our food energy and protein comes from only 15 plant and 8 animal species, with frightening effects for nutrition and food security[9]. In Ethiopia foods that most households consumed was cereals(barley, sorghum, wheat, rice) which is estimated to $90 \%$ of weekly consumption at least one of these cereals used in six of the last seven days. In addition, the country households were experienced $60 \%$ low dietary diversity and $40 \%$ medium diet dietary diversity scores $[10,11]$.

A large health burden can be caused due to deficiencies of Marco and micronutrients which was imposed lost productivity, increased susceptibility to diseases, impaired growth and development 
whereas intake of high diverse diets has been associated with lower rates of malnutrition[12, 13]. The prevalence of malnutrition among women of childbearing age were estimated as $15 \%$ are underweight and 35\% are overweight approximately across worldwide[14]. The dietary diversity scores prevalence was different across regions of Ethiopia including our study area. This confirmed with study conducted in Addis Ababa which reported household had 5.9\% low, 60.4\% medium and 33.7\% high[15], in Ahmara region 11.8\% low, 67.2\% medium and 21\% high[11] ,South Ahmara 65.7\% low and 34.3\% high[16] and SNNPR 41.9\% low, 48.5\% medium and 9\% high where High proportion of the households consumed vegetables (87.5\%) and cereals (78.7\%)[17]. Another study in Tanzania reported that more than $80 \%$ of the population were produce fruits and vegetables for consumption to increase dietary diversity[18, 19].

The dietary diversity has a number causes, with the most potential significant cause on the malnutrition. Several previous researcher suggested some socio demographic factors and clinical factors that associated to dietary diversity among pregnant women[20-23], children under five years[24-30] and households[11, 15-17, 31, 32], still little have been done regarding women under reproductive age which is base stage for fertility in human beings. However, A cross sectional study in Kenya reported that household gender, education level, age and family size were significantly associated with dietary diversity of women under childbearing in high agricultural potential areas[33].

In Ethiopia, Most of the women in the reproductive age group were consuming a diverse diet and those subjects with better dietary diversity score had their body mass index in the normal range[34]. Particularly, vulnerable group due to their greater micronutrient needs were women under reproductive age (15-49 years old)[35]. In low income country like Ethiopia where resource is limited low quality, monotonous diets were the norm. large dimension of women (98.3\%) based on monotonous food type whereas only $10.2 \%$ were found in the high dietary diversity score (DDS >6) means eating more than six food groups from ten in addition to very low intake of indispensable micronutrients rich foods such as Vitamin A and Iron[36].

Several studies conducted using cross sectional study design in Ethiopia which did not cover whole the geographical regions and administrative city. Ethiopia has nine administrative regions and two administrative city that exercised different norm, culture and multi-ethnic setting Some researcher used binary logistic regression and multiple regression to examine the effect of 
covariates on the dietary diversity practice of women which restricts the chronological order of dietary diversity (low, medium and high) among women under reproductive age when it have ordinal nature. However, this study employed ordinary logistic regression model that permit analyzing chronological prevalence of dietary diversity practice of women under childbearing age which used to examine the association between independent factors and dietary diversity score in Asaita Districts of Afar region using community based cross-sectional study design.

\section{Methods and Materials}

\section{Study area}

The study was conducted in Asaita woreda in zone 1(Awsi Rasu), Afar region North-Eastern Ethiopia. The zone is located in the Northern part of the region and about $65 \mathrm{~km}$ from the main town of the region (Samara) and $655 \mathrm{~km}$ the North East of Addis Ababa the capital city of Ethiopia. The woreda has latitude and longitude of $11^{\circ} 34 \mathrm{~N} 41^{\circ} 26 \mathrm{E}$ and an elevation of $300 \mathrm{~m}$. The dominant practice of woreda was pastoral and agro-pastoral system of livestock production. The mean temperature is between $30^{\circ} \mathrm{C}$ and $45^{\circ} \mathrm{C}$ per annum Afar regional state report [37].

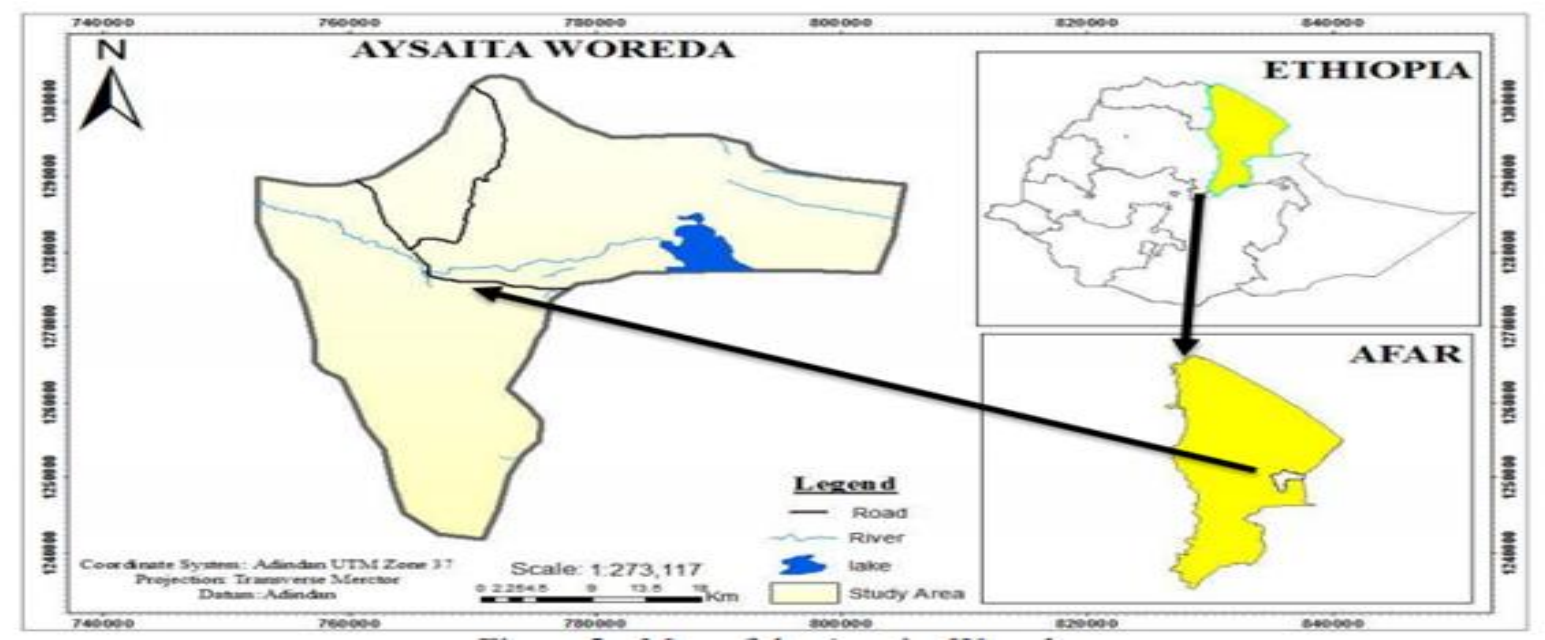

Fig. 1: Location map of study area of region and woreda.

\section{Study design and period}

A community based cross sectional study was conducted in February to March, 2020 among women under reproductive age (15-49) years that enrolled in nutritional status and its determinants whereas women below 15 years were excluded. This makes the sample size was 422 for Women in childbearing age. 


\section{Study population, sample size and sampling procedure}

The study considered all women under reproductive age found in Asaita woreda at Afar Regional state and selects a sample following the laws of the statistical theory of sampling that help to make valid inferences about the population based on the data obtained from the sample which ascertain the degree of accuracy of the results. Single population proportion was used to compute Sample size and the total sample size required $(\mathrm{N})=\mathrm{n}+$ non-response of respondents. Assuming $95 \%$ confidence interval with $5 \%$ margin of error, $\mathrm{Z}_{\alpha / 2}=1.96$ and $10 \%$ probability for nonresponse rate. We obtained $\mathrm{n}=\frac{Z_{\frac{\alpha}{2}}^{2} p q}{d^{2}}$ where $\mathrm{p}$ is the prevalence of the attribute $(51.4 \%)$ taken from previous research done in Addis Ababa[38].

$$
n=\frac{1.96^{2} * 0.514 *(1-0.514)}{0.05^{2}}=384
$$

Then, the sample $(n)=384+$ non response rate $(0.1 \times 384)=422$. Probability type of systematic sampling technique was used to get the study participants. The researcher was divided proportionally the sample size among the two kebeles to obtain a total number of childbearing women in the woreda and simple random sampling was employed during interview to select population size in each kebeles. Finally, the sample size was 422 .

\section{Data collection and measurements}

Primary data were collected for this study using self-administrative questionnaires.in procedure we followed the Food and Agriculture organization of United Nations definition of dietary diversity score which stated it as a qualitative 24-hour recall of all the food and drinks consumed by respondents (if measured at individual level) or any other household member (if measured at household level)[39]. One day recall time is subject to less recall error than a week or month recall period which in-lined with many studies in dietary diversity[40]. Likewise, the dependent variable considered in the study was women dietary diversity score that calculated from a 24 hour recall of women's nutritional status. Based on food items consumed in the past 24 hour, women were assigned the number of food groups they used, ranging from 0 to 8 or a score of 1 was given to each food groups consumed that attained maximum values of 8 points for women dietary diversity score. Then, according to sample of Food and Agriculture Organization[39] 
recommendation, women were classified into three groups:- $\leq 3$ Food groups as low dietary diversity, 4-5 food groups as medium dietary diversity and $\geq 6$ as high dietary diversity.

Based on the reviewed literature and the aims of current study we considered socio-demographic characteristics of women under reproductive age such as gender, household head, family size of male, family size of female, age, religion, educational status, relationship with child, ever attended school, occupation, ethnicity, number of room in house, kind of house, house window, having electric power, marital status of the household head were considered as independent variables. Moreover, women were interviewed they had their own radio, mobile, bank account, refrigerator, television and cart to know they are accessible with such technological device inlined to dietary diversity.

\section{Operational definitions}

- Dietary diversity can be defined as the number of different food groups consumed by an individual over 24-hours.

- Food groups are a collection of foods that contain a similar mix of nutrients.

- Inadequate dietary diversity: When women have low dietary diversity related to the standard recommendations.

- Minimum dietary diversity is the consumption of four or more food groups from the seven defined food groups for higher dietary quality and to meet basic nutritional needs [41].

- Healthier consumption pattern is consumption pattern with higher factor loading for food items strongly recommended by WHO to be consumed by women, particularly all the five major food groups (vegetables, fruit, meat, milk (dairy) and egg).

- Household is an individual who comprise a family unity and who live together under the same roof.

- Household size is the number of a person living together in one house.

\section{Statistical data analysis}

In current study, data were entered in Excel and exported to SPSS version-25 for further analysis. Frequency and percentages of each variable was calculated and displayed using tables. Descriptive measures for continuous variables were calculated and their normality distributions 
were checked. Chi-square test of association and ordinary logistic regression were employed to assess the potential determinants of dietary diversity of women and predict the dietary diversity score.

\section{Chi-square test of association}

In chi-square test, the null hypothesis makes a statements concerning how many cases are to be expected in each category if the null hypothesis if correct. It is based on the differences between the observed and the expected value of each category. The chi-square statistic is defined as:

$$
\chi^{2}=\sum_{i=1}^{n} \frac{\left(O_{i}-E_{i}\right)^{2}}{E_{i}}
$$

Where $\mathrm{O}_{i}$ is the observed number of cases in category $\mathrm{i}$, and $\mathrm{E}_{\mathrm{i}}$ is the expected number of cases in category i. The chi-square test used in this study to know the association between sociodemographic variables, food groups and dietary diversity of women. In addition, goodness of model also checked by applying chi-square test.

\section{Logistic regression}

Regression is a statistical procedure which attempts to predict the values of a given variable, (termed the dependent, outcome or response variable) based on the values of one or more variables (called independent variables, predictors, or covariates). Regression analysis is model building for the relationship between a dependent and one and/or more independent variables. In the regression if the response variable is continuous we can use the usual linear regression model whereas when the response variable is discrete, taking on two or more possible values the appropriate regression model is logistic regression which was proposed as alternative method in the late 1960s and early 1970s[42].

The problem of non-normality and heteroscadasticity lead to the model estimation method to be maximum likelihood after natural logarithm transformation of the odd ratio of the response because in logistic the relationship between the response with the set of explanatory variables is not linear hence the procedures used in the linear regression is extended to logistic regression. Logistic regression models are classified according to the type of categories of response variable 
as follows:-binary logistic regression model, multinomial logistic regression model and ordinal logistic regression models[43].

The binary logistic regression model is used to model the binary response variable, whereas the multinomial logistic regression is a simple extension of the binary logistic regression model where the response variable has more than two unordered categories. Ordinal logistic regression models are used to model the relationship between independent variables and an ordinal response variable when the response variable category has a natural ordering, this employed in current study.

\section{Ordinary logistic regression}

Ordinal logistic regression is an extension of binary logistic regression for analyzing ordinal response variable having more than two categories by considering the ordering of the response variable categories. This model is used to describe the relationship between an ordered categorical response (dependent) variable and one or more explanatory (independent) variables. There are different types of ordinal logistic regression models, the most commonly used are: the adjacent-category, the continuation-ratio, the proportional odds models, the unconstrained partial-proportional odds model, the constrained partial-proportional odds model[43].

\section{Proportional odds model}

Proportional Odds Model is used for modeling the response variable that has more than two levels with $\mathrm{K}$ set of explanatory variables by defining the cumulative probabilities, cumulative odds and cumulative logit for the J-1 categories of the response, this model simultaneously use all cumulative logits. A random sample is drawn from the joint distribution of (Y, X'), where $\mathrm{Y}$ is an ordinal response and $\mathrm{X}^{\prime}=\left(\mathrm{X}_{1}, \mathrm{X}_{2}---, \mathrm{X}_{\mathrm{n}}\right)$ is a vector of independent variables. Let $\pi_{\mathrm{j}}\left(\mathrm{X}^{\prime}\right)$ denote the classification probabilities $\operatorname{Pr}\left(\mathrm{Y}=\mathrm{j} / \mathrm{X}^{\prime}\right)$ of response variable $\mathrm{Y}, \mathrm{j}=1,2,-\cdots, \mathrm{k}$ at any value $X^{\prime}=\left(X_{1}, X_{2},-\cdots, X_{n}\right)$ for a set of explanatory variables $X_{1}, X_{2},-\cdots, X_{s}$. The cumulative probability can be given as:- $\pi_{j}(X)=p(Y \leq j / X)=P_{1}+P_{2}+P_{3}+\ldots+P_{j}$. for $\mathrm{j}=1,2,---, \mathrm{J}-1$. $\Pi_{\mathrm{j}}$ (X) is the probability of being at or below category $\mathrm{j}$ given that $\mathrm{k}$ set of predictors [43]. The odds of the cumulative probabilities of the response variable for the J-1 categories:- 


$$
\operatorname{odds}\left[\pi_{j}(X)\right]=\frac{\pi_{j}(x)}{1-\pi_{j}(x)}, j=1,2, \ldots, J-1 .
$$

The logarithm of the odds first $\mathrm{j}-1$ cumulative probabilities

$$
\ln \left(\text { odds }\left[\pi_{j}(X)\right]\right)=\ln \left(\frac{\pi_{j}(x)}{1-\pi_{j}(x)}\right), j=1,2, \ldots, J-1 .
$$

The relationship between the response variable and the set of predictors is not linear in ordinal logistic regression model. The logistic regression function uses the logit transformation of $\pi_{j}(X)$ cumulative probabilities of the response,

$$
\pi_{j}(X)=p(Y \leq j / X)=\frac{\exp \left(\alpha_{j}-\left(\beta_{1} x_{1}+\beta_{2} x_{2}+\ldots+\beta_{k} x_{k}\right)\right)}{1+\exp \left(\alpha_{j}-\left(\beta_{1} x_{1}+\beta_{2} x_{2}+\ldots+\beta_{k} x_{k}\right)\right)}
$$

Likewise the transformation of equation [4] to the logit for the matter of interpretation ordinal logistic regression result can be as follows:-

$$
\log i t\left[P(Y \leq j / X]=\alpha_{j}-\sum_{j=1}^{J-1} \beta_{j} X_{j}, j=1,2, \ldots, J-1\right. \text {. }
$$

Equation [5] is called the proportional odds model (POM) to predict cumulative logits across J-1 response categories. This model estimates $\ln \left(\right.$ Odds) of being at or below the $\mathrm{j}^{\text {th }}$ category and assume that there is a linear relationship between the logits and the parallel regression lines and hence, this model estimates simultaneously multiple equations of cumulative probability. The model is solved for each category of the dependent variable except the last category.

In the model each logit has its own $\alpha_{j}$ term called the threshold value and their values do not depend on the values of the independent variables and the $\beta_{k}$ 's are the logistic regression coefficients and the estimated values of these parameters show the direction and the strength of the relationship between the explanatory variables and the logit (log odd) of the dependent variable. The result is interpreted as the effect (more likely and less likely) of the estimated category of the independent variables relative to the reference category on the log odds being in higher levels of the categories of the dependent variable. 


\section{Wald test for a single predictors}

The Wald test is used to see the significance of a single explanatory variable in the model. The Wald test statistic is the square of the ratio of the estimated coefficient to its standard error and is defined as: $\mathrm{W}=\left[\frac{\hat{\beta}}{S E(\hat{\beta})}\right]^{2}$ Under the null hypothesis $\mathrm{H}_{0}: \beta_{\mathrm{i}}=0, \mathrm{i}=1,2,--, \mathrm{k}$ and $\mathrm{W}$ has a chisquare distribution with one degree of freedom.

\section{Goodness-of-fit measures}

In this study the goodness of fit measure was used to assess how well a model fit the data. To check the goodness of fit Pearson chi-square and deviance goodness of fit were employed which compare the observed and expected values having chi-square distribution with n-p degrees of freedom. Both goodness-of-fit statistics should be used only for models that have reasonably large expected values in each cell. The model fit the data well when the test value of Statistic is small and the observed significance level being large. The researchers fail to reject the null hypothesis that the model fits the data well when the observed significance level for the statistic is large since good models have large observed P-values.

\section{Results}

\section{Socio-economic and demographic variables}

A total of 422 sampled women under reproductive age (WRA) of dietary diversity at Asaita districts, Afar region were used. An abridged WRA of dietary diversity information reveals that the proportion of household headship with respect to their gender categories of male and female headship were $87.4 \%$ and $12.6 \%$ respectively. Most of the women (83.6\%) were not attended school in the districts. Similarly, the distribution of women's education status revealed that $361(85.5 \%)$ had illiterate, 21(5.0\%) 1-12 school, 17(4.0\%) college education and the remaining 23(5.5\%) were university education. Regarding marital status of women about 23(5.5\%) single, $369(87.4 \%)$ married, 22(5.2\%) were divorced and the rest $8(1.9 \%)$ were widowed. The remaining characteristics had similar fashion of interpretations were attached here in detailed information below in Table 1 . 
A Chi-square test showed that except region and ethnicity, all characteristics were statistically significant association with dietary diversity of women at $5 \%$ level of significance. This implies that the presence those factors have effect to change the status of dietary diversity practice for women in the fertile women (Table 1).

Table 1. Socio-economic and demographic variables of fertile women

\begin{tabular}{|c|c|c|c|}
\hline Variable & Categories & Count (\%) & Chi-square (P-value) \\
\hline \multirow[t]{2}{*}{ Household headship } & Male & $369(87.4)$ & \multirow{2}{*}{$20.206(0.000)^{\mathrm{a}}$} \\
\hline & Female & $53(12.6)$ & \\
\hline \multirow[t]{2}{*}{ Relationship of child } & By birth & 401(95.0) & \multirow[t]{2}{*}{$11.955(0.003)^{\mathrm{a}}$} \\
\hline & Not by birth & $21(5.0)$ & \\
\hline \multirow[t]{2}{*}{ Attended school } & Yes & $69(16.4)$ & \multirow[t]{2}{*}{$65.921(0.000)^{\mathrm{a}}$} \\
\hline & No & $353(83.6)$ & \\
\hline \multirow[t]{4}{*}{ Marital status } & Single & $23(5.5)$ & \multirow[t]{4}{*}{$27.258(0.000)^{\mathrm{a}}$} \\
\hline & Married & $369(87.4)$ & \\
\hline & Divorced & $22(5.2)$ & \\
\hline & Widowed & $8(1.9)$ & \\
\hline \multirow[t]{4}{*}{ Education status } & Illiterate & $361(85.5)$ & \multirow[t]{4}{*}{$71.987(0.000)^{\mathrm{a}}$} \\
\hline & $1-12$ school & $21(5.0)$ & \\
\hline & College education & $17(4.0)$ & \\
\hline & University education & $23(5.5)$ & \\
\hline \multirow[t]{5}{*}{ Current occupation } & Daily laborer & $17(4.0)$ & \multirow[t]{5}{*}{$72.553(0.000)^{\mathrm{a}}$} \\
\hline & Farmer & $3(0.7)$ & \\
\hline & Government employer & $18(4.3)$ & \\
\hline & House wife & $369(87.4)$ & \\
\hline & Merchant & $15(3.6)$ & \\
\hline \multirow[t]{3}{*}{ Religion } & Orthodox & $16(3.8)$ & \multirow[t]{3}{*}{$9.038(0.060)$} \\
\hline & Muslim & $405(96.0)$ & \\
\hline & Protestant & $1(0.2)$ & \\
\hline \multirow[t]{5}{*}{ Ethnicity } & Amahara & $28(6.7)$ & \multirow[t]{5}{*}{$8.370(0.398)$} \\
\hline & Tigray & $3(0.7)$ & \\
\hline & Oromo & $4(0.9)$ & \\
\hline & Afar & $386(91.5)$ & \\
\hline & Welayta & $1(0.2)$ & \\
\hline \multirow[t]{2}{*}{ Kind of house } & Finished floor & $84(19.9)$ & \multirow[t]{2}{*}{$42.928(0.000)^{\mathrm{a}}$} \\
\hline & Rudimentary & $338(80.1)$ & \\
\hline \multirow[t]{2}{*}{ House of window } & Yes & $370(87.7)$ & \multirow[t]{2}{*}{$17.128(0.000)^{\mathrm{a}}$} \\
\hline & No & $52(12.3)$ & \\
\hline \multirow[t]{2}{*}{ House of electricity } & Yes & $370(87.7)$ & \multirow[t]{2}{*}{$17.128(0.000)^{\mathrm{a}}$} \\
\hline & No & $52(12.3)$ & \\
\hline \multirow[t]{2}{*}{ Radio } & Yes & $220(52.1)$ & \multirow[t]{2}{*}{$7.644(0.022)^{\mathrm{a}}$} \\
\hline & No & $202(47.9)$ & \\
\hline \multirow[t]{2}{*}{ Mobile phone } & Yes & $257(60.9)$ & \multirow[t]{2}{*}{$40.755(0.000)^{\mathrm{a}}$} \\
\hline & No & $165(39.1)$ & \\
\hline Bank account & Yes & $244(57.8)$ & $50.087(0.000)^{\mathrm{a}}$ \\
\hline & No & $178(42.2)$ & \\
\hline Refrigerator & Yes & $109(25.8)$ & $85.975(0.000)^{\mathrm{a}}$ \\
\hline & No & $313(4.2)$ & \\
\hline
\end{tabular}




\begin{tabular}{|llll|}
\hline Television & Yes & $137(32.5)$ & $49.603(0.000)^{\mathrm{a}}$ \\
\cline { 2 - 3 } & No & $285(67.5)$ & \\
\hline Cart & Yes & $29(6.9)$ & \\
\cline { 2 - 3 } & No & $393(93.1)$ & \\
& \multicolumn{2}{|c|}{} &
\end{tabular}

\section{Measures of central tendency for continuous variables}

The mean age of the women under reproductive age was $36.53 \pm 7.667$ standard deviation. In regard to family size in male and female were approximately the mean of 3 participants, between mean \pm SD $(2.28 \pm 1.138)$ and 2.04 \pm 0.914 with the range of $0-5$ and 1-5 family size was presented respectively. The average number of room in house used for WRA was 1.20 \pm 0.400 SD with the range of 1-2 room(s) per household.

Table 2. Descriptive Statistics for continuous variables of WRA at Afar region, Aysaita districts

\begin{tabular}{|lllll|}
\hline Variable & Minimum & Maximum & Mean & Sd \\
\hline Age & 15 & 49 & 36.53 & 7.667 \\
\hline Family size of male & 0 & 5 & 2.28 & 1.138 \\
\hline Family size of female & 1 & 5 & 2.04 & 0.914 \\
\hline No. of room in your house & 1 & 2 & 1.20 & 0.400 \\
\hline Dietary diversity score & 1 & 8 & 4.17 & 1.112 \\
\hline
\end{tabular}

\section{Distribution of $\mathbf{2 4}$ hours food categories score of fertile women}

Off 14 food categories, the result revealed that the average of food categories were mean \pm SD (4.17 \pm 1.112$)$ among scores varied from 1 to 8 food categories (Table 2). According to the group formed, about $13.0 \%$ of the respondent was in the minimum dietary diversity (less than or equal to three) groups, $78.5 \%$ of participants were a medium diversity (four to five) groups and the remaining $8.5 \%$ were in the high diversity (greater than or equal to six) groups.

A participants almost full day consumed food category was grains $100 \%$, vegetables and beans or peas were the second and third most eaten food groups of $90.5 \%$ and $78.0 \%$ were presented respectively. Notably, the vegetables or roots and other types of meat or poultry were minimally consumed $2(0.5 \%)$ and $3(0.7 \%)$. Likewise, meat made from animal organs, fish or sea food whereas fresh or dried and nuts or seeds were totally not consumed food groups (Figure 2). As the test result revealed in Table 3, one sample t-test shows that all food groups were statistically significant $(\mathrm{P}<0.05)$.

Table 3. Proportion of WRA eating commodity of 14 food categories with in the past 24 hours

\begin{tabular}{|c|c|c|c|c|}
\hline Food categories & Categories & Frequency (\%) & Mean \pm Sd & $\begin{array}{l}\text { One sample t- test (P- } \\
\text { value) }\end{array}$ \\
\hline \multirow[t]{2}{*}{ Grains } & Yes & $422(100.0)$ & $1.00 \pm 0.000$ & - \\
\hline & No & - & & \\
\hline Vegetables or roots & Yes & $2(0.5)$ & $2.00 \pm 0.069$ & $446715(n \cap n \cap)^{\mathrm{a}}$ \\
\hline
\end{tabular}




\begin{tabular}{|c|c|c|c|c|}
\hline & No & $420(99.5)$ & & \\
\hline \multirow[t]{2}{*}{ White root and tubers } & Yes & 49(11.6) & \multirow[b]{2}{*}{$1.88 \pm 0.321$} & \multirow{2}{*}{$88.634(0.000)^{\mathrm{a}}$} \\
\hline & No & 373(88.4) & & \\
\hline \multirow[t]{2}{*}{ Dark green leafy vegetables } & Yes & $99(23.5)$ & \multirow[t]{2}{*}{$1.77 \pm 0.424$} & \multirow{2}{*}{$61.272(0.000)^{\mathrm{a}}$} \\
\hline & No & $323(76.5)$ & & \\
\hline \multirow[t]{2}{*}{ Fruits that are dark yellow or orange inside } & Yes & $98(23.2)$ & \multirow[t]{2}{*}{$1.77 \pm 0.423$} & \multirow{2}{*}{$61.604(0.000)^{\mathrm{a}}$} \\
\hline & No & 324(76.8) & & \\
\hline \multirow[t]{2}{*}{ Other fruits } & Yes & 122(28.9) & \multirow[t]{2}{*}{$1.71 \pm 0.454$} & \multirow{2}{*}{$54.805(0.000)^{\mathrm{a}}$} \\
\hline & No & $300(71.1)$ & & \\
\hline \multirow[t]{2}{*}{ Any other vegetables } & Yes & 382(90.5) & \multirow[t]{2}{*}{$1.09 \pm 0.293$} & \multirow{2}{*}{$41.663(0.000)^{\mathrm{a}}$} \\
\hline & No & $40(9.5)$ & & \\
\hline \multirow[t]{2}{*}{ Meat made from animal organs } & Yes & - & \multirow[t]{2}{*}{$2.00 \pm 0.000$} & \multirow[t]{2}{*}{-} \\
\hline & No & $422(100.0)$ & & \\
\hline \multirow[t]{2}{*}{ Other types of meat or poultry } & Yes & $3(0.7)$ & \multirow[t]{2}{*}{$1.99 \pm 0.084$} & \multirow{2}{*}{$364.598(0.000)^{\mathrm{a}}$} \\
\hline & No & 419(99.3) & & \\
\hline \multirow[t]{2}{*}{ Eggs } & Yes & $50(11.8)$ & \multirow{2}{*}{$1.88 \pm 0.324$} & \multirow{2}{*}{$87.711(0.000)^{\mathrm{a}}$} \\
\hline & No & 372(88.2) & & \\
\hline \multirow[t]{2}{*}{ Fish or seafood whereas fresh or dried } & Yes & - & \multirow[t]{2}{*}{$2.00 \pm 0.000$} & \multirow[t]{2}{*}{-} \\
\hline & No & $422(100.0)$ & & \\
\hline \multirow[t]{2}{*}{ Beans or peas } & Yes & $329(78.0)$ & \multirow[t]{2}{*}{$1.22 \pm 0.415$} & \multirow{2}{*}{$35.659(0.000)^{\mathrm{a}}$} \\
\hline & No & $93(22.0)$ & & \\
\hline \multirow[t]{2}{*}{ Nuts or seeds } & Yes & - & \multirow[t]{2}{*}{$2.00 \pm 0.000$} & \multirow[t]{2}{*}{-} \\
\hline & No & $422(100.0)$ & & \\
\hline Milk or milk products & Yes & 207(49.1) & $1.51 \pm 0.501$ & $41.433(0.000)^{\mathrm{a}}$ \\
\hline & No & $215(50.9)$ & & \\
\hline Dietary Diversity (Dependent variable) & $\leq 3$ & $55(13.0)$ & & \\
\hline & $4-5$ & $331(78.5)$ & & \\
\hline & $\geq 6$ & $36(8.5)$ & & \\
\hline
\end{tabular}

\section{Proportion of women under reproductive age who used food types}

Grains were every day eaten food categories from 14 food items in 24 hours before data gathering day. Any other vegetables were the most eaten food items from 14 food items in 24 hours before data gathering day.

A 382(90.5\%) of the reproductive women participated that they consumed items equipped as of any other vegetables. The minority of women reproductive age were $2(0.5 \%)$ and $3(0.7 \%)$ responded that they ate foods prepared from vegetables or roots and other types of meat or poultry. While, meat made from animal organs, fish or sea food whereas fresh or died and nuts or seeds were totally not consumed food groups. 


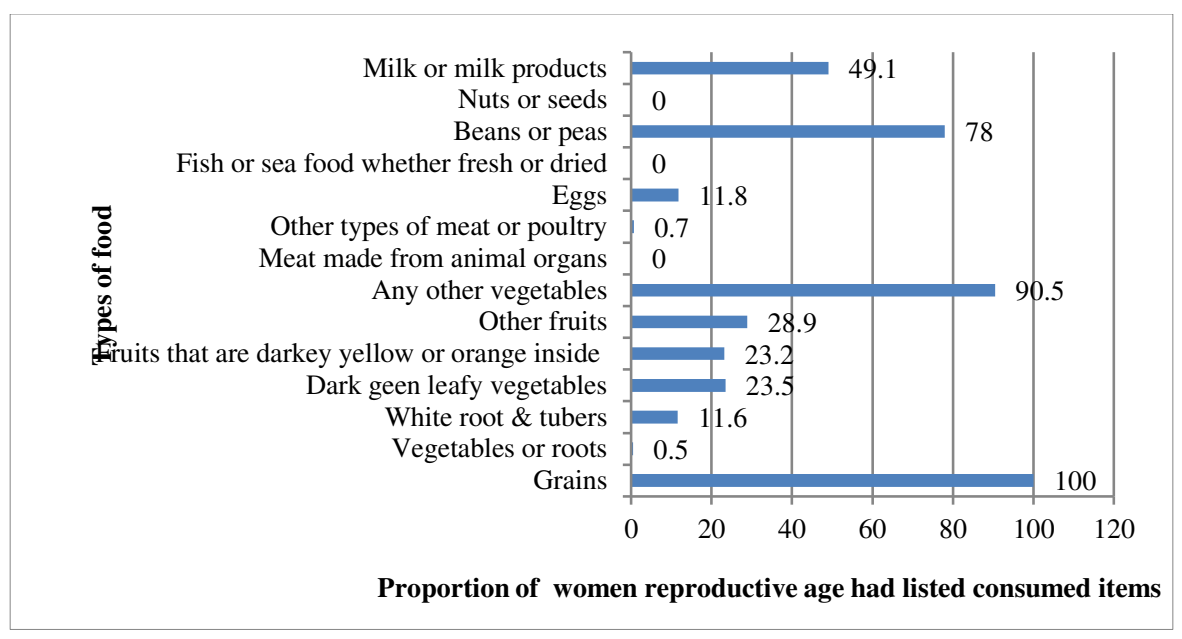

Fig. 2. Categorical distribution of consumed items to create them highly verified

In Figure-3 showed that, from a total of 422 dietary diversity of women reproductive age participants about 55(13.0\%) were under minimum dietary (less than or equal to three) items, $331(78.5 \%$ ) were optimal dietary (four to five) items and $36(8.5 \%$ ) were maximum dietary (greater than or equal to six) items.

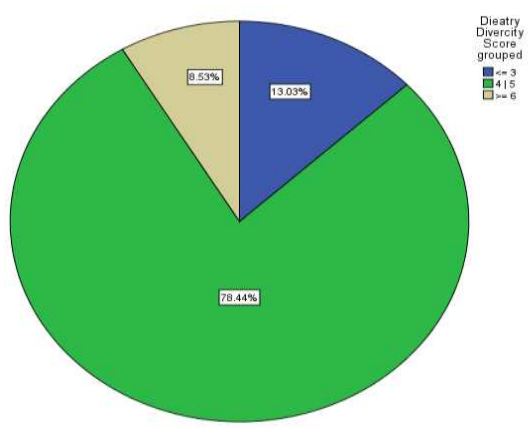

Fig. 3. Proportion of food items of reproductive women

\section{Ordinary logistic regression model}

In this study, OLRM was utilized to handle the relationships of the food items among women reproductive age (15-49) years. This model some time called with Base-Line Cumulative Logit (BCL) or Cumulative Logit Models (CLM), can have quantitative and qualitative predictors, intercept terms, etc. Multi-category logit models, $\mathrm{Y}$ has $\mathrm{J}$ categories, $\mathrm{J}>2$. Extensions of likelihood ratio test for nominal and ordinal Y assume a multi-nominal distribution for Y.

OLRM utilized to manage influence of socio-economic and demographic variables versus food groups among women reproductive age committed by intimate family. The deviance Chi-square 
test $G^{2}=(D f=763, P=1.000)$ revels statistically significance at 1.00 that means $>5 \%$, that show the data clearly fitted OLRM in this study (Table 4). Therefore, we can generalize as a statistically insignificant variation of value in the forecasted and observed value explored under the OLRM. A Cumulative Logit Model (CLM) has form: $\log i t[P(Y \leq j)]=\alpha_{j}+\beta_{i j} x_{i j}$; where, $\mathrm{j}=1,2,3 ; \mathrm{i}=1,2,3,4$.

The contingency table data so can test blimey a model fitted. A deviance is use to test that all parameters are not equal to zero in the model. Deviance $=G^{2}=299.617, \mathrm{df}=763, \mathrm{P}$-value $=1.000$ for $H_{0}$ : model holds with linear trends for all explanatory variables.

The explanatory variables can be both qualitative and quantitative variables in this model where a last category of a variable was considered as a baseline group. The result was included two quantitative and eight qualitative factors are statistically significant $(\mathrm{P}<5 \%)$, whereas a minimally one group should positively or negatively affecting dietary diversity among reproductive age. Statistically influencing explanatory variables were considered in the OLRM were family size of male, family size of female, marital status, education level, window, cell phone, bank, refrigerator, television and cart $(\mathrm{P}<0.05)$.

The estimated odds of being "low dietary" instead of "high dietary" multiplies by [OR=0.576, 95\% CI: $(0.377,0.879)]$ for each unit increased by 1 of male family size of household. Odds of existing "low dietary" instead of "high dietary" multiplies by [OR=0.665, CI: $(0.448,0.988)]$ for each increased by 1 unit of female family size household. The estimated odds of a married status response is in low dietary rather than high dietary diversity scores are [OR=294195.561, (CI: $1.669,51842701505)]$ times estimated odds for windowed response. The odds of an education level is in low dietary rather than high dietary diversity scores are $\left[\mathrm{OR}_{1}=0.065, \mathrm{OR}_{2}=0.026\right.$ and $\left.\mathrm{OR}_{3}=0.026\right]$ times estimated odds for higher education.

The estimated odds had a window's response is in low dietary rather than high dietary scores are $[\mathrm{OR}=2.793$, (CI: 1.138, 6.853)] times estimated odds for had no window's response. The odds had a cell phone's is in low dietary rather than high dietary scores are [OR=20.005, (CI: 6.507, 61.503)] times estimated odds for had no cell phone's. The odds had a bank account's is in low dietary rather than high dietary scores are $[\mathrm{OR}=70.457$, (CI: 16.359, 303.445)] times estimated 
odds for had no bank account's. The estimated odds had a refrigerator's for household user is in low dietary rather than high dietary scores are [OR=11.752, (CI: 2.208, 62.545)] times estimated odds for had no refrigerator's for household user. The odds had a television's access is in low dietary rather than high dietary scores are $[\mathrm{OR}=0.034$, (CI: 0.006, 0.185)] times estimated odds for had no television's access. The estimated odds had a cart's response is in low dietary rather than high dietary scores are $[\mathrm{OR}=0.002$, (CI: 0.001, 0.006)] times estimated odds for had no cart's response.

Table 4. Multivariable analysis of dietary diversity of fertile women at 95\% CI for coefficient

\begin{tabular}{|c|c|c|c|c|c|c|c|c|c|}
\hline \multirow[t]{2}{*}{ Variables } & \multirow[t]{2}{*}{ Categories } & \multirow[t]{2}{*}{$\hat{\beta}$} & \multirow[t]{2}{*}{$\operatorname{S.E}(\hat{\beta})$} & \multirow[t]{2}{*}{ Wald } & \multirow[t]{2}{*}{ Df } & \multirow[t]{2}{*}{ P-Value } & \multirow[t]{2}{*}{$\operatorname{Exp}(\hat{\beta})$} & \multicolumn{2}{|c|}{ Ci of $\operatorname{Exp}(\hat{\beta})$} \\
\hline & & & & & & & & Lower & Upper \\
\hline F. Size Male & & -0.552 & 0.216 & 6.548 & 1 & $0.011^{\mathrm{a}}$ & 0.576 & 0.377 & 0.879 \\
\hline F. Size Female & & -0.408 & 0.202 & 4.065 & 1 & $0.044^{\mathrm{a}}$ & 0.665 & 0.448 & 0.988 \\
\hline \multirow{3}{*}{$\begin{array}{l}\text { Marital Status } \\
\text { (Windowed } \\
\text { (Refr.)) }\end{array}$} & Single & 18.203 & 853.490 & 0.000 & 1 & 0.983 & 80438220.46 & 0 & 0.000 \\
\hline & Married & 12.592 & 6.163 & 4.174 & 1 & $0.041^{\mathrm{a}}$ & 294195.561 & 1.669 & 51842701505 \\
\hline & Divorce & -2.897 & 1.744 & 2.760 & 1 & 0.097 & 0.055 & 0.002 & 1.684 \\
\hline \multirow{3}{*}{$\begin{array}{l}\text { Education } \\
\text { (University ed. } \\
\text { (Refr.)) }\end{array}$} & Illiterate & -2.736 & 1.365 & 4.018 & 1 & $0.045^{\mathrm{a}}$ & 0.065 & 0.004 & 0.941 \\
\hline & 1-12 school & -3.632 & 1.255 & 8.382 & 1 & $0.004^{\mathrm{a}}$ & 0.026 & 0.002 & 0.309 \\
\hline & College education & -3.717 & 1.256 & 8.763 & 1 & $0.003^{\mathrm{a}}$ & 0.024 & 0.002 & 0.285 \\
\hline Window & Yes $(\mathrm{No}(($ Refr. $))$ & 1.027 & 0.458 & 5.035 & 1 & $0.025^{\mathrm{a}}$ & 2.793 & 1.138 & 6.853 \\
\hline Cell phone & Yes (No((Refr.)) & 2.996 & 0.573 & 27.370 & 1 & $0.000^{\mathrm{a}}$ & 20.005 & 6.507 & 61.503 \\
\hline Bank account & Yes (No((Refr.)) & 4.255 & 0.745 & 32.604 & 1 & $0.000^{\mathrm{a}}$ & 70.457 & 16.359 & 303.445 \\
\hline Refrigerator & Yes (No((Refr.)) & 2.464 & 0.853 & 8.343 & 1 & $0.004^{\mathrm{a}}$ & 11.752 & 2.208 & 62.545 \\
\hline Television & Yes (No((Refr.)) & -3.386 & 0.867 & 15.238 & 1 & $0.000^{\mathrm{a}}$ & 0.034 & 0.006 & 0.185 \\
\hline Cart & Yes (No((Refr.)) & -7.171 & 1.076 & 44.425 & 1 & $0.000^{\mathrm{a}}$ & 0.002 & 0.001 & 0.006 \\
\hline \multirow[t]{2}{*}{ Pearson Test } & & \multicolumn{2}{|c|}{ Chi-square } & \multicolumn{3}{|c|}{ Df } & \multicolumn{3}{|c|}{ Sig. } \\
\hline & & \multicolumn{2}{|c|}{1983.645} & \multicolumn{3}{|c|}{763} & \multicolumn{3}{|c|}{$0.000^{\mathrm{a}}$} \\
\hline \multicolumn{2}{|l|}{ Deviance Test } & \multicolumn{2}{|l|}{299.617} & \multicolumn{3}{|c|}{763} & \multicolumn{3}{|c|}{1.000} \\
\hline
\end{tabular}

$\mathrm{F}=$ Family, a $=$ Statistically significant at $5 \%, \mathrm{Df}=$ Degree of freedom, $\mathrm{Ci}=$ Confidence interval, Refr.= Reference group

\section{Discussion of the study}

In this study, around $13.0 \%$ of the respondent was in the minimum dietary diversity (less than or equal to three) groups, $78.5 \%$ of participants were a medium diversity (four to five) groups and the remaining $8.5 \%$ were in the high diversity (greater than or equal to six) groups in past one day. The study revealed that, almost all (100\%) and $90.5 \%$ of the women reproductive age had eaten grains and vegetables respectively in the past one day and $0.5 \%$ had not eaten vegetables or roots items in the past 24 hours. The outcome of this study is minimum than that of the other outcome in Laikipia, Kenya[21], and Southern Ethiopia [45]. Furthermore, many studies in developing countries have documented that their dietary sources are mainly cereal based [46]. 
The variables such as family size of male, family size of female, marital status, education level, window, cell phone, bank account, refrigerator, television and cart additionally revealed a robust relationship in the OLRM. The result is again in line with [20]. Again in [45] study had associated to socioeconomic factors for the reason that food groups increases as education level increase. Reproductive age among women who had cell phones in lower dietary diversity rather than higher dietary diversity were more than twenty times more likely than that of the participants had not cell phone. The outcome was parallel with studies done at South Gondar, Ethiopia[20].

An odds who had a television's is in low dietary rather than high dietary are $[\mathrm{OR}=0.034$, $(\mathrm{CI}$ : 0.006, 0.185)] times estimated odds who had not television'. It delivers recognized a television contact which teaches a participants were obtained a diversified food items for health improvement promoting. A participants had a savings is again statistically ominously related with food items. The odds of having saving is in low dietary rather than high dietary diversity are $[\mathrm{OR}=70.457$, (CI: 16.359, 303.445)] times estimated odds who had no bank account's. It is in line with the study piloted at South Africa everyplace families through minimum food items through additionally record needy, rarer families having cash in a bank account [47] and also totals for food items had stayed exposed in line to economic factors [19].

The estimated odds had a refrigerator's for household user is in low dietary rather than high dietary scores are $[\mathrm{OR}=11.752,(\mathrm{CI}: 2.208$, 62.545)] times estimated odds for had no refrigerator's for household user. The estimated odds had a window's response is in low dietary rather than high dietary scores are $[\mathrm{OR}=2.793$, (CI: 1.138, 6.853)] times estimated odds for had no window's response. The estimated odds had a cart's response is in low dietary rather than high dietary scores are $[\mathrm{OR}=0.002$, $(\mathrm{CI}: 0.001,0.006)]$ times estimated odds for had no cart's response.

The estimated odds of being "low dietary" instead of "high dietary" multiplies by [OR=0.576, 95\% CI: $(0.377,0.879)]$ for each increase by one in male family size of the household. Odds of existing "low dietary" instead of "high dietary" multiplies by [OR=0.665, $(0.448,0.988)]$ for every unit increase by one in female family size of household. The odds of an education level is in low dietary rather than high dietary diversity scores are $\left[\mathrm{OR}_{1}=0.065, \mathrm{OR}_{2}=0.026\right.$ and $\left.\mathrm{OR}_{3}=0.026\right]$ times estimated odds for higher education. Studies on [48, 49], note that women 
allocated in both educated and family size statistically significantly good generous distribution of the household economical to healthy items. It is primarily reason family size and education status of women tends to had better consciousness and appreciative of dietary healthiness welfares [50]. Even if a family size and education status of women is an empowered of women.

The estimated odds of a married status response is in low dietary rather than high dietary diversity scores are $[\mathrm{OR}=294195.561,(\mathrm{CI}: 1.669,51842701505)]$ times estimated odds for windowed response. The studies of amount of food items had shown relationship with demographic factors [51].

\section{Conclusion}

An average food items amount in reproductive women were 36.53 and $13.0 \%, 78.5 \%$ and $8.5 \%$ of women reproductive age having minimum, optimal and maximum food items practice was presented in that order. Almost all eaten food groups were grains 100\% and vegetables and beans or peas were the most commonly eaten the second and third most eaten food groups of $90.5 \%$ and $78.0 \%$ were presented respectively. Notably, the vegetables or roots and other types of meat or poultry were minimally consumed $0.5 \%$ and $0.7 \%$. Likewise, meat made from animal organs, fish or sea food whereas fresh or dried and nuts or seeds were totally not consumed food groups. Hence, family size of male and female, marital status, education level, having cell phone, bank account, refrigerator, television and cart had powerfully related with food items applies in women under reproductive age at Asaita districts of Afar regional state, Ethiopia.

\section{Limitations of the study}

In this study there are different food items in the families which affect the pattern of intake capacity in the past one day (twenty four hours). The study environment is a primary data collected at a point of time, because it does not reveal the association between dependent and independent variables clearly.

\section{List of Abbreviations}

WRA: Women Reproductive Age, DDS: Dietary Diversity Score, OLRM: Ordinary Logistic Regression Model, OR: Odds Ratio, Sd: Standard deviation, Ci: Confidence interval, SPSS-25: Statistical Package for Social Science-25, Df: Degree of freedom 


\section{Declarations}

\section{Ethical Approval and Consent to Participate}

The moral permission had been gotten from Statistics Department, Haramaya university, Dire Dawa, Ethiopia. The ethical approval was obtained from department of Statistics at Haramaya University with formal letter referenced as HU-Stat/101/20.

\section{Consent for Publication}

It is not related in this study.

\section{Availability of Data and Materials}

We used cross-sectional study design for this investigation obtained at Asaita Districts, Afar Regional State. Alebachew Abebe (Asst. Prof.) will be the contact person if someone wants to request the data from this study. The contact person Email: aleb.abebe@yahoo.com.

\section{Competing Interests}

The authors declare that we have no competing interests.

\section{Funding}

The funding of the study not valid.

\section{Authors Contributions}

Both authors design a data gathering format, pilot survey, editing and/ or clearing data and analyzed and interpretation of data by both Million W. (MSc) and Alebachew A. (Asst. Prof.). We are also edited the document and gave critical comments. Both authors were edited and checked all issues in the study.

\section{Acknowledgments}

Thank you a lot for all participants in this study giving a concrete suggestion and/ or ideas. And also, the second acknowledgment forward for Afar region, Asaita districts administrators for giving permission to gathered a primary data in the households.

\section{Authors' Information}


Alebachew Abebe is a senior Assistant Professor in Biostatistics at College of Computing and Informatics, Haramaya, Ethiopia and also having earlier eight manuscripts and one proceeding.

Million Wesenu is a senior lecturer in Biostatistics at College of Computing and Informatics, Haramaya, Ethiopia and also having earlier four manuscripts.

\section{References}

[1] M. Ruel, "November 2003. Operationalizing dietary diversity: a review of measurement issues and research priorities," J. Nutr, vol. 133, no. 11.

[2] L. M. Waswa, I. Jordan, J. Herrmann, M. B. Krawinkel, and G. B. Keding, "Community-based educational intervention improved the diversity of complementary diets in western Kenya: results from a randomized controlled trial," Public health nutrition, vol. 18, no. 18, pp. 34063419, 2015.

[3] M. Arimond et al., "Simple food group diversity indicators predict micronutrient adequacy of women's diets in 5 diverse, resource-poor settings," The Journal of nutrition, vol. 140, no. 11, pp. 2059S-2069S, 2010.

[4] C. Daniels, "Dietary diversity as a measure of Women's diet quality in resource-poor areas: results from metropolitan Cebu, Philippines site," Wanshington: Food and Nutrition Technical Assistance Project II (FANTA-2), 2009.

[5] W. Girma and T. Genebo, "Determinants of nutritional status of women and children in Ethiopia," 2002.

[6] W. H. Organization, Indicators for assessing infant and young child feeding practices: part 1: definitions: conclusions of a consensus meeting held 6-8 November 2007 in Washington DC, USA. World Health Organization, 2008.

[7] A. Hatløy, J. Hallund, M. M. Diarra, and A. Oshaug, "Food variety, socioeconomic status and nutritional status in urban and rural areas in Koutiala (Mali)," Public health nutrition, vol. 3, no. 1, pp. 57-65, 2000.

[8] J. Hoddinott and Y. Yohannes, Dietary diversity as a household food security indicator. Food and Nutrition Technical Assistance Project (FANTA), Academy for ..., 2002.

[9] Food and A. O. o. t. U. States, The State of Food Insecurity in the World, 2013: The Multiple Dimensions of Food Security. Food and Agricultural Organization of the United Nations, 2013.

[10] D. Goshu, B. Kassa, and M. Ketema, "Measuring diet quantity and quality dimensions of food security in rural Ethiopia," Journal of Development and Agricultural Economics, vol. 5, no. 5, pp. 174-185, 2013.

[11] G. Mekuria, Y. Wubneh, and T. Tewabe, "Household dietary diversity and associated factors among residents of finote selam town, north west Ethiopia: a cross sectional study," $B M C$ nutrition, vol. 3, no. 1, p. 28, 2017.

[12] S. S. Lim et al., "A comparative risk assessment of burden of disease and injury attributable to 67 risk factors and risk factor clusters in 21 regions, 1990-2010: a systematic analysis for the Global Burden of Disease Study 2010," The lancet, vol. 380, no. 9859, pp. 2224-2260, 2012.

[13] B. M. Popkin and M. Slining, "New dynamics in global obesity facing low-and middle-income countries," Obesity reviews, vol. 14, pp. 11-20, 2013.

[14] W. H. Organization, "World health statistics: a snapshot of global health," Ginebra: Organización Mundial de la Salud, 2012.

[15] Z. N. Hassen, "Determinants of Household Dietary Diversity and Nutritional Status of Women in Reproductive Age Group: The Case of Addis Ababa City, Ethiopia," University of Nairobi, 2013. 
[16] D. Misker, B. Misker, and G. Ayele, "House hold dietary diversity and associated factors in Mirab Abaya wereda Southern Ethiopia; community based cross sectional study," Divers Equal Health Care, vol. 13, no. 4, pp. 293-6, 2016.

[17] G. Addis, Z. Asfaw, and Z. Woldu, "The role of wild and semi-wild edible plants to household food sovereignty in Hamar and Konso communities, South Ethiopia," 2013.

[18] V. Afari-Sefa, A. Tenkouano, C. O. Ojiewo, J. Keatinge, and J. d. A. Hughes, "Vegetable breeding in Africa: constraints, complexity and contributions toward achieving food and nutritional security," Food Security, vol. 4, no. 1, pp. 115-127, 2012.

[19] J. Keatinge, R.-Y. Yang, J. d. A. Hughes, W. Easdown, and R. Holmer, "The importance of vegetables in ensuring both food and nutritional security in attainment of the Millennium Development Goals," Food Security, vol. 3, no. 4, pp. 491-501, 2011.

[20] M. Desta, M. Akibu, M. Tadese, and M. Tesfaye, "Dietary diversity and associated factors among pregnant women attending antenatal clinic in Shashemane, Oromia, Central Ethiopia: a crosssectional study," Journal of nutrition and metabolism, vol. 2019.

[21] W. Kiboi, J. Kimiywe, and P. Chege, "Determinants of dietary diversity among pregnant women in Laikipia County, Kenya: a cross-sectional study," BMC Nutrition, vol. 3, no. 1, p. 12, 2017.

[22] F. Ali, I. Thaver, and S. A. Khan, "Assessment of dietary diversity and nutritional status of pregnant women in Islamabad, Pakistan," Journal of Ayub Medical College Abbottabad, vol. 26, no. 4, pp. 506-9, 2014.

[23] S. E. Lee, S. A. Talegawkar, M. Merialdi, and L. E. Caulfield, "Dietary intakes of women during pregnancy in low-and middle-income countries," Public health nutrition, vol. 16, no. 8, pp. 13401353, 2013.

[24] G. E. Berhe Gebremichael and N. Assefa, "Dietary diversity practice and associated factors among infants and young children in Haramaya town, Ethiopia," International Journal of Public Health, vol. 6, no. 3, pp. 243-250, 2017.

[25] F. Yonas, "Infant and young child feeding practice status and associated factors among mothers of under 24-month-old children in Shashemene Woreda, Oromia region, Ethiopia," Open Access Library Journal, vol. 2, no. 07, p. 1, 2015.

[26] A. Gatahun and M. Abyu, "Dietary diversity feeding practice and determinants among children aged 6-23 months in Kemba Woreda, southern Ethiopia implication for public health intervention," Nutrition \& Food Sciences, 2015.

[27] D. Gessese, H. Bolka, A. A. Abajobir, and D. Tegabu, "The practice of complementary feeding and associated factors among mothers of children 6-23 months of age in Enemay district, Northwest Ethiopia," Nutrition \& Food Science, 2014.

[28] M. Saaka, A. Larbi, S. Mutaru, and I. Hoeschle-Zeledon, "Magnitude and factors associated with appropriate complementary feeding among children 6-23 months in northern Ghana," BMC Nutrition, vol. 2, no. 1, p. 2, 2016.

[29] R. Victor, S. K. Baines, K. E. Agho, and M. J. Dibley, "Factors associated with inappropriate complementary feeding practices among children aged 6-23 months in T anzania," Maternal \& child nutrition, vol. 10, no. 4, pp. 545-561, 2014.

[30] S. Bedada Damtie, T. Benti Tefera, and M. Tegegne Haile, "Dietary Diversity Practice and Associated Factors among Children Aged 6-23 Months in Robe Town, Bale Zone, Ethiopia," Journal of Nutrition and Metabolism, vol. 2020, 2020.

[31] J. Ochieng, V. Afari-Sefa, P. J. Lukumay, and T. Dubois, "Determinants of dietary diversity and the potential role of men in improving household nutrition in Tanzania," PloS one, vol. 12, no. 12, p. e0189022, 2017. 
[32] D. A. Amugsi, A. Lartey, E. Kimani-Murage, and B. U. Mberu, "Women's participation in household decision-making and higher dietary diversity: findings from nationally representative data from Ghana," Journal of Health, Population and Nutrition, vol. 35, no. 1, p. 16, 2016.

[33] M. W. Gitagia, R. C. Ramkat, D. M. Mituki, C. Termote, N. Covic, and M. J. Cheserek, "Determinants of dietary diversity among women of reproductive age in two different agroecological zones of Rongai Sub-County, Nakuru, Kenya," Food \& nutrition research, vol. 63, 2019.

[34] S. Shashikantha, M. Sheethal, and B. Vishma, "Dietary diversity among women in the reproductive age group in a rural field practice area of a medical college in Mandya district, Karnataka, India," International journal of community medicine and. Public Health, vol. 3, no. 3, pp. 746-9, 2017.

[35] L. E. Torheim, E. L. Ferguson, K. Penrose, and M. Arimond, "Women in resource-poor settings are at risk of inadequate intakes of multiple micronutrients," The Journal of nutrition, vol. 140, no. 11, pp. 2051S-2058S, 2010.

[36] T. A. Zerfu, M. Umeta, and K. Baye, "Dietary diversity during pregnancy is associated with reduced risk of maternal anemia, preterm delivery, and low birth weight in a prospective cohort study in rural Ethiopia," The American journal of clinical nutrition, vol. 103, no. 6, pp. 1482-1488, 2016.

[37] M. Pelling, Adaptation to climate change: from resilience to transformation. Routledge, 2010.

[38] A. Worku, S. Mekonnen Abebe, and M. M. Wassie, "Dietary practice and associated factors among type 2 diabetic patients: a cross sectional hospital based study, Addis Ababa, Ethiopia," SpringerPlus, vol. 4, no. 1, p. 15, 2015/01/13 2015, doi: 10.1186/s40064-015-0785-1.

[39] G. Kennedy, M. Razes, T. Ballard, and M. C. Dop, "Measurement of dietary diversity for monitoring the impact of food based approaches," in International symposium on food and nutrition security, Rome, 2010.

[40] G. L. Kennedy, M. R. Pedro, C. Seghieri, G. Nantel, and I. Brouwer, "Dietary diversity score is a useful indicator of micronutrient intake in non-breast-feeding Filipino children," The Journal of nutrition, vol. 137, no. 2, pp. 472-477, 2007.

[41] W. H. Organization, "Improving nutrition outcomes with better water, sanitation and hygiene: practical solutions for policies and programmes," 2015.

[42] A. F. Cabrera, "Logistic regression analysis in higher education: An applied perspective," Higher education: Handbook of theory and research, vol. 10, pp. 225-256, 1994.

[43] D. W. Hosmer Jr, S. Lemeshow, and R. X. Sturdivant, Applied logistic regression. John Wiley \& Sons, 2013.

[44] G. Chakona and C. Shackleton, "Minimum dietary diversity scores for women indicate micronutrient adequacy and food insecurity status in South African towns," Nutrients, vol. 9, no. 8, p. 812, 2017.

[45] N. BELIE, "DIETARY DIVERSITY AND ASSOCIATED FACTORS AMONG LACTATING WOMEN IN WORETA TOWN, SOUTH GONDAR ZONE, ETHIOPIA," 2020.

[46] M. Saaka, J. Oladele, A. Larbi, and I. Hoeschle-Zeledon, "Dietary diversity is not associated with haematological status of pregnant women resident in rural areas of northern Ghana," Journal of nutrition and metabolism, vol. 2017, 2017.

[47] S. Drimie, M. Faber, J. Vearey, and L. Nunez, "Dietary diversity of formal and informal residents in Johannesburg, South Africa," BMC public health, vol. 13, no. 1, p. 911, 2013.

[48] H. A. Mbwana, J. Kinabo, C. Lambert, and H. K. Biesalski, "Determinants of household dietary practices in rural Tanzania: Implications for nutrition interventions," Cogent Food \& Agriculture, vol. 2, no. 1, p. 1224046, 2016/12/31 2016, doi: 10.1080/23311932.2016.1224046. 
[49] M. S. Morseth, N. K. Grewal, I. S. Kaasa, A. Hatloy, I. Barikmo, and S. Henjum, "Dietary diversity is related to socioeconomic status among adult Saharawi refugees living in Algeria," BMC Public Health, vol. 17, no. 1, p. 621, 2017/07/03 2017, doi: 10.1186/s12889-017-4527-x.

[50] A. Taruvinga, V. Muchenje, and A. Mushunje, "Determinants of rural household dietary diversity: The case of Amatole and Nyandeni districts, South Africa," 2013.

[51] M. Savy, Y. Martin-Prével, P. Traissac, S. Eymard-Duvernay, and F. Delpeuch, "Dietary diversity scores and nutritional status of women change during the seasonal food shortage in rural Burkina Faso," (in eng), J Nutr, vol. 136, no. 10, pp. 2625-32, Oct 2006, doi: 10.1093/jn/136.10.2625. 